\section{Board the eurostar}

\author{
Europe's science meeting is getting bigger and \\ better. Now's the time to get involved for 2012.
}

I magine an audience of several thousand researchers, policymakers, educators and members of the public gathering to hear and talk about science, its applications and its impacts. Imagine discussing your work with this audience. If that idea appeals to you, keep reading, and act on what follows by the end of this month.

When a small group of researchers launched the Euroscience lobbying organization in 1997 (see www.euroscience.org), no one envisaged that its most visible manifestation would be a meeting that has steadily evolved and grown in importance over the years: the Euroscience Open Forum (ESOF). Since its launch in Stockholm in 2004, the biennial meeting has attracted a larger and more diverse range of participants, retaining a central focus on the natural sciences but with increasing attention to industry and the social sciences.

At the last meeting, in Turin in 2010, there were more than 4,000 attendees from 71 countries. According to surveys of the attendees, the 120-plus scientific sessions attracted high ratings for interest and comprehensibility and for the variety of themes. The number of journalists attending has grown to more than 300 .

Europe's cities have competed to host the meeting. Next year's, on 12-16 July 2012, will be in Dublin (see www.dublinscience2012.ie).
Whatever the current financial situation, over the past decade Ireland's investment in science has grown at double the rate of the rest of its economy. This has seen the quantity and impact of the country's scientific publications grow over the past five years, and resulted in marked improvements in the international rankings of its universities. The Irish government has backed ESOF2012 energetically from the start.

Some of the themes of ESOF2012 address the frontiers of scientific knowledge. They include, for example, the power and limitations of our knowledge of the genotype with respect to our understanding of the phenotype, deep-space astronomy, quantum computation, and information science. Other themes are more philosophical: the concept of free will in cognitive science; how science provides meaning; whether e-mail is the end of history. Still others lie at the forefront of applications - 'nutriceuticals' and other innovative aspects of food, and, of course, the science and the issues surrounding energy, environment and the climate.

These themes provide a framework, but the creative spark in the ESOF meeting has always arisen in the sessions, in which researchers and others have often provoked vigorous but critically minded interest - the audiences are far from passive.

A typical session involves four panellists discussing science or technologies and the issues they give rise to. In past years, competition to run scientific sessions has been fierce, with a rejection rate for the 2010 meeting of about $50 \%$. Encouragingly, the traffic to the proposals website shows that there is already substantial interest for the meeting next year. Readers are encouraged to submit their own proposals instructions are at go.nature.com/wq39ya.

\section{Gold mine}

\section{A trove of worms found in the deep subsurface biosphere illustrates the ubiquity of life.}

Z oologists of a certain age will remember with affection Animals Without Backbones, a classic 1938 elementary textbook by Ralph Buchsbaum that quotes a (sadly uncredited) researcher on the ubiquity of nematodes, or roundworms. Were all the matter on Earth, it says, to be made transparent apart from nematodes the grass, the trees, the people, the animals, even the ground beneath our feet - the shapes of all these things would still be discernible, if ghostly, from their burden of worms.

It is therefore fitting, if not hugely surprising, that nematodes have now been found in the deep subsurface biosphere, a realm hitherto believed accessible only to microbes. The nematodes recovered from gold-mine workings under South Africa - reported on page 79 of this issue - are the first multicellular organisms to be discovered in such a subterranean setting.

Although underground worms may bring to mind the imaginings of science-fiction writers, these are not monsters. The cramped spaces between the grains of rocks, where these creatures presumably graze on bacteria, have straitened them. At hardly half a millimetre in length, they would barely deserve even a slither-on role in Tremors, the scifi spectacular that stars enormous worms that destabilize buildings. And our golden nematodes would be as fleas before an elephant compared with the majestic sandworms of Dune, which were the size of jumbo jets.

Yet their discovery is encouraging, even heartening, for it demonstrates, once again, that once life appears, it is hard to extinguish and that there are few, if any, habitats in which living things might not survive, even thrive, no matter how seemingly unpromising the circumstances. Even today, when you may think that we have shaken every tree and looked under every stone on the planet, new creatures hove into view. It is rare, nowadays, to discover large vertebrates as yet unknown to science, yet such discoveries are still made.

Molecular methods have extended the reach of those formerly equipped only with traps and butterfly nets, allowing trawls of entire habitats for new forms of life - in the sea, in the upper air and even in the rich inner spaces of our guts. There is probably no slagheap too toxic, no nuclear-waste dump too radioactive, no smoking fumarole too fuming and no icy firn too frigid that it cannot be colonized by some enterprising microbe. A promise of a carbon source, a whisper of redox potential, and life will arrive. (Indeed, to encourage such endeavours, Nature promises a $500 \mathrm{~g}$ jar of Marmite to the research group that can identify the organism that digests this savoury spread. Tip: it is probably endemic in the intestines of Britons, to many of whom Marmite is an obsession, and absent in the more sensitive stomachs of Danes, who last week threatened to ban the comestible because of its evil added vitamins.)

Perhaps the habitats least explored and prospected for life are the most familiar: soil, sediments in ponds, and the seashore - the home of the meiofauna, creatures that make their living between particles of minerals and detritus. Meiofauna creatures at their largest are just at the verge of unaided visibility, down to about 40 micrometres in diameter - a world literally in the interstices, too small for every day, but too big to trouble micro- or molecular biologists. The meiofauna offer a community of tiny arthropods and a range of creatures otherwise encountered only in the dustier (and therefore most fascinating) pages of textbooks. This is the realm in which nematodes rule - and a kingdom to which we can now add, as Buchsbaum's unheralded scientist almost predicted, the ground deep, deep beneath our feet.

In some ways their world is hidden, inaccessible and unknown.In others it is in plain sight and all around us. To pull a nematode from
DNATURE.COM To comment online, click on Editorials at: go.nature.com/xhunqu the deep subsurface biosphere is an achievement. But we needn't look as far as that to find wonders that are new and strange - those who look most carefully will see a universe in a grain

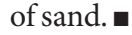

